\title{
The Effect of Using Simulation Activities on Developing Algerian EFL Students' Speaking and Listening Proficiency
}

\begin{abstract}
:
Crystallising Comprehension, retaining long-term outcomes, and raising the rate of interest have put extra up-to-date demands on EFL teachers. These demands have led teachers to look for recent effective innovations in language teaching. Recently, there has been much demand for the active learning techniques to encourage learners step one foot outside the stereotyped learning pattern. The need for a self-generated communication has completed the picture for teachers. By consensus, simulation came to remedy EFL learners need for communication and convey the teachers' aim. Thus, the aim of this study was to implement the simulation activities in English language teaching to second year EFL students at University of Constantine 1. A quasi experimental method was used to test the efficacy of simulation in developing EFL learners' speaking and listening proficiencyand a sample compromised two experimental groups participated in the study. After analysing the pre-test and post-test results, the findings revealed that simulation has successfully developed the EFL learners' speaking and listening proficiency with greater effective impact of simulation activities on listening than on speaking proficiency.
\end{abstract}

Key words: simulation activities, speaking proficiency, listening proficiency

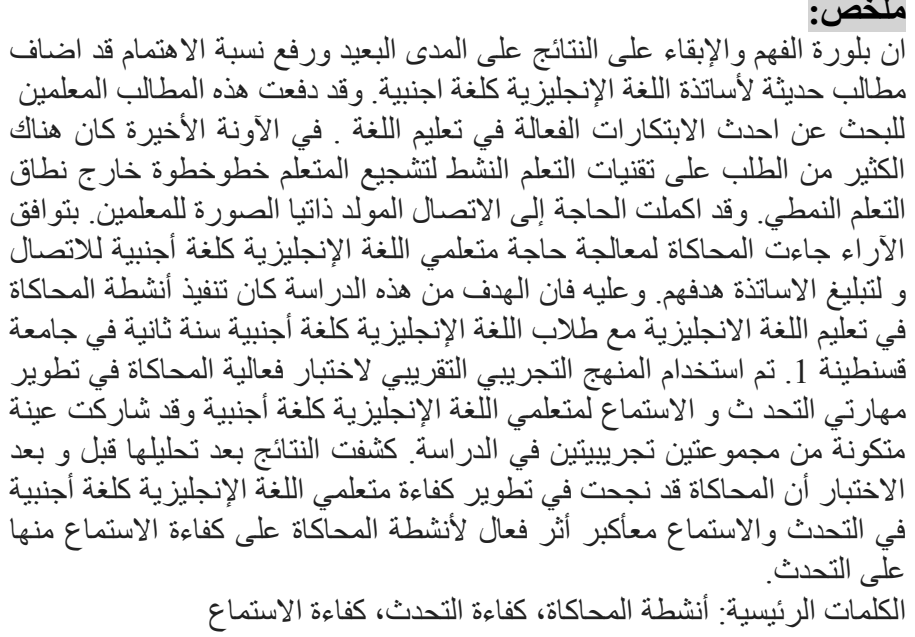

\section{Karima CHERGUI}

Faculty of Letters and Languages Department of Foreign Languages University of Mentouri Constantine

\section{Introduction:}

Algerian students' English speaking and listening proficiency level hinges upon the teaching methods. The teaching norm dominating in higher education is mainly based on learning what 'I have to know' and not 'what I should be able to do'.. 
As a result many students fail to recognise what they can do or even trust their ability to do what they learned because of the isolation of their language competence from the outside world.It is this disconnection of language teaching and real life situations that brought this paper into line with bridging this gap. Within the domination of communicative language teaching, which focuses on engaging and immersing students in real-environment, an increasing tendency towards innovative language teaching method raised. Reviewing the pedagogical recent practices, interactive language teaching seems to gainhuge popularity. In addition to its integration of speaking and listening, interaction insures the use of language purposefully and promotes communication skills. Communication is the concern of language teachers and learners. However, EFL Teachers use the communicative activities such as discussions, interviews, and information gap, etc. which mostly focus on one language skill over the other, which is in most cases speaking.

Additionally, Algerian EFL students have fewer opportunities to listen in face-to- face interactions because one way listening (watching television, listening to audio, video, and to teachers) is the dominating teaching method. Nevertheless, what challenges learners, is the real life listening where there is no second chance for repetition. For stimulating learners listening capacity, "Listening must be done in real time" (Brown, 2006, p.4). Simulation comes to remedy this dilemma as it models real-life situations where speaking and listening are interactively used and activates effective communication as a need to achieve different functional purposes and not as a goal (Jones, 1982).

Simulation use dates back to more than fifty years ago, however, its first integration was in non-ELT domains like, psychology, business, law, and medicine, etc. Although this method has grown rabidly in the pedagogical literature, there seems a paucity of research on the impact of this method on developing EFL learners' speaking skills and listening comprehension ability. Moreover, there is insufficient evidence to support the effect of "far more varied" communication skills that simulation provides (Jones, 1982) on challenging learners to elevate speaker-hearer communicative acts.The mutual need for better oral skills teaching, andthe importance of speaking and listening crucial role in communication were enough reasons to design this study. Consequently, this study was conducted to investigate the impact of simulation activities on improving EFL learners' speaking and listening proficiency at the University of Constantine 1.

Speaking in EFL Teaching

No doubt that speaking is the priority for many EFL learners and teachers especially with referring to it as "the verbal use of language to communicate with others" (Fulcher, 2003, P. 23) and communication is a tool for satisfying needs and hence to survive (Barker \& Gaut, 2002). EFL learners, in their turn, use English as a medium for exchanging their ideas and thoughts 
with others to maintain in daily communication. Speaking replicates communication; thus, it involves the components of communicative competence; grammatical, sociolinguistic, discourse, strategic, pragmatic, and actional competences (Canal, 1983; Bachman, 1990; Celce-Murcia et al., 1995).

Bygate (1987) claims that being able to speak a language, is a problem in EFL teaching. As a result, an understanding of the mechanics of this skill is required by teachers. Thornbury (2005) says that speaking is weighed on the basis of extralinguistic knowledge, involving speakers' knowledge of the topic, culture, context and interlocutors; sociolinguistic knowledge, the knowledge about social values, behavioral norms of a given society; and the linguistic knowledge that involves understanding the genre (pp. 11-25). Harmer (2007) in turn suggests that "thinking of speaking in terms of purpose, participation and planning helps us to provide speaking activities in all six categories - and in different combinations of these categories" (P.343). Drawing a conclusion from Harmer's suggestion, teaching speaking entails careful consideration for the function that spoken language may play, that is to say; transactional to convey and exchange information, or interactional to maintain good relations with people; for the nature of spoken language construction, jointly constructed, i.e., interactive, or solely constructed i.e., non-interactive; and for the way of planning the speech; planned in advance such as a lecture, or unplanned like phone conversation to ask for train timetable (Thornbury, 2005, pp. 134).Many researchers provide multiple activities that teachers may use to teach speaking: acting from a script, communication games like information-gap games, television and radio games, discussions, debates, prepared talks, questionnaires, interviews, problem solving, jigsaw tasks, role play and simulation (Harmer, 2007; Brown, 2001). Littlewood (1981) argues that speaking activities can be either social or communicative.

Most speaking is done in face-to-face exchanges. Thus, when speaking is used for communication, learners' linguistic, strategic, lexical, and discourse knowledge are manifested to achieve functional purpose with a partner in a social context. Hence, speaking is taught to realize social, functional, and pragmatic goals in the form of conversation. In essence, the interaction nature of conversation allows no speaking without listening.

\section{Listening in EFL Teaching}

The assortment of the language system in any speech can cause difficulty for learners in their speaking and listening; fast, instantaneous, unplanned natures of spoken discourse, accent, low information load and context may also depict an obstacle towards listening comprehension (Richards, 2008; Buck, 2001; O'Malley and Valdez Pierce, 1996,), but not as much as the interactive nature of speech (Brown, 2001). All the former characteristics of speech depict more problems for listeners and exert more attention towards listening. By 
consensus, listening comprehension depends on the understanding of the spoken discourse (Richards, 2008). Richards provides two processes for encoding the spoken discourse; Bottom-up and top-down processes.Practically speaking, Brown (2001) states that when listeners are listening intensively, they are applying Bottom-up strategies, meaning to follow the hierarchal organisation of the linguistic system; sounds, words, clauses, sentences and texts. While top-down process refers according to Field (2008) to the use of context and co-text to identify unclear words. Hence, background knowledge, topic knowledge, and situational or context knowledge are intertwined together to depict comprehensible input for the listeners of foreign language.

In EFL teaching, listening has been perceived for a long time as one way process where listeners answer some comprehensible questions, reflecting understandingof vocabulary items and the gist of the text they heard; however, in one-way listening, learners listen without any control over what they listen, no asking for repetition, no rephrasing for unclear ideas, and no confirmation feedback for meaning are allowed. To ensure better effective listening, a new tendency has raised towards two-way listening.

The understanding of the native speaker listening capacity allowed researchers and teachers to widen the scope of teaching listening by dealing with listening as an active skill.Vandergrift (1997) coins the active nature of listening with interaction. Xiaoxian and Yan (2010) further explain interactive listening as follows:

Interactive listening takes place in a communicative situation, in which the listener, taking an active role (as a participant or an addressee), listens and gives responses such as signaling comprehension, requesting clarifications, negotiating meanings, etc. In so doing, the listener, in collaboration with the speaker, solves communication problems, shapes the discourse, and accomplishes certain goals of interaction (P.22).

Communicative Language Teaching (CLT) has changed the beliefs of teaching and learning; the aim became no longer the acquisition of language but the use of language. As a result, speaking and listening are treated as compulsory skills that work together in the form of meaning negotiation to elicitcommunication where learners share mutual influence (Barker \& Gaut, 2002) in the interaction. The shift becomes tangible which emphasizes the cooperative active learning and the manifestation of comprehension through the equivalent attention paid to both speaking and listening skills.

\section{Simulation}

Simulation has been intertwined with the language techniques in the university classrooms for decades. This technique was integrated in the classroom in the late 1950's and early 1960's, and after this decade, simulation 
has increasingly been used as a teaching technique (Shaw, 2010). The implementation of this technique came under the name of "active learning" where students are not supposed to only practice learned knowledge but to construct it as well.

Simulation has been defined as "a reality of function in a simulated and structured environment" (Jones, 1982, p.5). In other words, simulation involves the impersonation of a function and perceives it as real, and adaptation to real aspects of environment. By function, Jones (ibid) means the duties and responsibilities that a role exerts like manager, ecologist, reporter, survivor, etc. However, the simulation is not controlled as participants participate in the simulation by their own character, experience, skills, and knowledge (Jones, 1983; Harmer, 2007; Shaw, 2010).

Simulated environment is a setting for learning that models the real world context to be studied. Due to limited access to real world environment, the dangerous "contact, interaction or consequences between the participants and the world outside the classroom" (Jones, ibid, p. 5), learners low competency to understand and perform adequately in the outside world system the classroom seems the best place to resemble the outside world and generate a safe simulation. A simulation is based on structured situation which involves problem solving and decision making (Jones, ibid). Consequently, the efficacy of the simulation reveals when participants come to a decision. (Harmer, 2007)

The main concern of controllers in simulation is fulfilling the former conditions and ensure the automatic driven communication that is generated by the instinct resulted from the responsibilities and duties of the function. In line with this, Jones(1982) and Harmer (2007) claim that fluency in the first place and not formal accuracy is what matters in a simulation. Adhering to fluency simulation is seen as an opportunity to practice a full range of communication skills such as analysis, advertising, negotiations, journalism, etc. (Jones, 1982; Jones, 1983)

The advantages of simulation are numerous, starting from its enthusiastic nature to its long-term impact. As simulations are self-generated and involving, motivation raises in participants' behaviour (Harmer, ibid). Jones (1982) claims that the motivation is inherent in the duties, responsibilities, and the circumstances of the event. The signs of motivation, the enjoyment, pleasure, and excitement are seen when the participants taste the delight of solving a problem or making an effective decision. Furthermore, Jones (ibid) and Harmer (ibid) mention an important benefit of the simulation which is breaking down the common classroom pattern student-teacher interaction to be student-student interaction and hence the teacher becomes the controller who facilitates and monitors the learning process, while the students become active participants responsible for their own learning and consequently a wider range of language skills will be included in the learners' repertoire. This orientation will exert 
more confidence, natural self-generated communications, and a sense of security as participants apply decision-making skills and solve situation-based problems in a controlled environment without being terrified by the consequences. Simulations, on one hand, have long term impact as participants remember "what they tried to communicate, how they tried to do it and what happened as a result" (Jones, ibid, p. 9) even years after the simulation. On the other hand, simulation can be a valuable assessment tool that tells the students' progress.

As mentioned earlier simulations are in their most part interactive. They encourage different forms of social interactions. Simulations teach participants how to function in different social contexts. Thus, leaners learn how to achieve various functions through language, e.g., requesting; apologising, complaining, agreeing, etc. and hence practice a full range of language functions like presenting an opinion, arguing, discussing to make a decision, interviewing, or solving a problem,etc. Consequently, simulations give a chance for learners to focus on the adjacency pairs and turn taking. The basic assumption is that those functions, behaviours, communication skills and the improvisation nature of the simulation activities prepare learners for possible interactions that may occur in the future in outside world.

Talking about simulation and role play, one can easily regard the similarities but hardly distinguish them in terms of differences. However, there is a difference even if it is slightly noticeable.Simulation is considered as a complex form of role plays as Ladousse (1987) puts it: "role play activities range from highly-controlled guided conversations at one end of the scale, to improvised drama activities at the other; from simple rehearsed dialogue performance, to highly complex simulated scenarios" (p.3). Hence, the difference is a matter of degree as participants in simulation take part in an event andfeel free to adapt their own vision in solving the problem and making decision. In this respect, Jones (1982) declares that simulation "is not taught" (p.2), but role plays are taught in terms of what should learners say and do. Participants in simulation do not play roles but they fulfil a function and accordingly Jones (1983) indicates that participants do not pretend to be someone else but adopt only "a new surname". Simulation and role play took different aims as simulation aims at encouraging communication which occurs as a survival need, however, role play's aim is to practise typical activities they will probably perform in real life.

\section{Research Design and Methodology Participants}

A quasi-experimental design was adopted to conduct this study. Second year EFL students were selected as the population of this study since they had beenless exposed to communicative activities, had less materials focussed solely on speaking and listening skills (two terms). A sample population of two 
experimental groups from the population were provided to the teacher by the department of letters and English language. Thus, the teachers did not have control over the participants' assignment to both experimental groups. However, only students who have the attendance rate of $80 \%$ and more were allowed to be part of experimental groups. The total number of participants amounted to Thirty-six students between 20-21 years old, each group equally includes 18 subjects.

\section{Research Questions}

The questions that this research is attempting to answer are:

- Does the use of simulation activities improve second year EFL students' speaking proficiency at Constantine University 1 ?

- Does the use of simulation activities improve second year EFL students' listening proficiency at Constantine University 1 ?

\section{Hypothesises}

1. Second year EFL students' speaking proficiency will improve after the implementation of simulation activities that will reveal the statistical significant difference between the pre/post-tests of both experimental groups.

2. Second year EFL students' listening proficiency will improve after the implementation of simulation activities that will reveal the statistical significant difference between the pre/post-tests of both experimental groups.

\section{Data collection procedures}

Two proficiency tests were used to assess students speaking and listening proficiency at the beginning (pre-test) and at the end (post-test) of the first semester of the academic year (2015). The reason behind using speaking skills tests are "to elicit enough speech to allow a rating to take place" (Fulcher, 2003 , p. 50). Noteworthy, the two tests were separated by the intervention (simulation activities).

Weir (2005) claims that "the assessment of spoken language is potentially more problematic thanthe rating of written scripts" (P. 192). To solve this problem, audio recordings of students speaking test were collected, and then converted into written scripts. Afterwards, the latter were transcribed to help the researcher encode students' spoken language into ordinal scores for grammar, pronunciation, and vocabulary, ratio scores to measure speech rate and nominal scores to encode fluency and interactive communication, on the one hand.

On the other hand, listening assessment was not too far from the traditional assessment; consequently, a one way listening took place for listening assessment as Buck claims (2001), it is more practical to use the noncollaborative testing (P. 98). The pre/post listening tests were designed on two types of assessment; first selected-response assessment in the form of false/true 
questions and multiple choice questions. These questions according to Buck (ibid) encourage students to re-adjust their inferences and interpretations. The Second type is the constructed-response assessment which includes gap filling to assess students' intensive listening, and questions that require short answers; the latter are said to be easy to score (Buck, ibid).

\section{Materials used in the study}

The materials used in this study were the pre/post-tests materials and materials for the treatment (simulations). The materials for the pre/post-tests speaking skills included one topic as the format of the speaking test was interaction-based. The rationality for this tendency towards 'direct' type of speaking test (Weir, 2005, p.144) is due to the fact that all simulations "involve a substantial amount of interaction between the participants" (Jones, 1982, p.7). This inspiration brought the test format into line with discussion format where each pair of students discusses a given topic. The researcher informed the participants, in the pre-speaking skills test, that they are supposed to discuss with a partner the following topic: "whether women should work after getting married or not?" And "do you think that life today is better than in the past?" as the topic for the post-speaking skills test. Both experimental groups took the test in the same day with the help of another teacher.

To ensure a spontaneous performance, the researcher informed the participants that the discussion is undertaken without time restriction to free them from time pressure and allow more space to fluency to occur. They were given two minutes to think over their opinion and ideas individually. The researcher was the responsible for evaluating participants speaking tests' recordings. The materials for both pre/post-tests listening consisted of four questions; each had a different type and aim (selected or constructed-response assessment and intensive or extensive listening) as mentioned above. The students were given ten minutes to read all the questions, and then the recorded texts played four times to allow students answer the questions. The researcher analysed the answers giving each participant a mark out of 20 .

The treatment materials included series of scenarios, each delivered in three sessions (four hours and a half) following the task-based lesson sequence; pre-task, during task and post-task. Hence, the whole course took eight weeks. The themes of the simulation were based on solving problems, making decision, and interacting as declared by Jones (1982). Thefive scenarios of the simulation dealt with: job recruitment, teachers' meeting, podcast, news program, repairing the university building(plenary meeting). In each simulation, the students passed three stages; in the pre-task stage, they got all the vocabulary and language function they need to perform in the simulation through watching video or listening to audio recording that replicate the situation they are supposed to perform. During the task, they listened to the briefing of the simulation, i.e., the explanation of what to do in the simulation, 
then, they start their own simulation. The post-task stage was the debriefing of the simulation where students analysed their mistakes and achievements through self-assessment, peer feedback, and teachers' feedback. Students also got an idea about the failures of the simulation so that they avoid them in the next one.

\section{Data Analysis}

In order to analyse students' spoken language, recordings were used as mentioned above and converted to written scripts. A set of criteria were established to help generate accurate score for students speaking proficiency. The criteria used in assessing students spoken language in this study are;grammatical resource, lexical resource, discourse management, pronunciation and interactive communication (Galaczi, 2005, p.17). The analytic approach was applied and the former criteria were treated. The reason behind choosing this approach over the holistic one is the intention of reaching a formative conclusion of students' achievement in each criterion (Weir, 2005). The analytic speaking scale used in this research is adopted from Weir (1993), (cited in Weir, 2005, pp.195-6). Some remarks were taken from Fulcher (2003) speaking construct definition to refine the rating scale for each criterion according to the students' level and the research's aim and conditions (See appendix). The scoring process happened on five levels as mentioned by Weir (1993):

\begin{tabular}{|l|l|}
\hline Criteria & Marks \\
\hline Fluency & 4 out of 20 \\
\hline Pronunciation & 4 out of 20 \\
\hline Vocabulary & 4 out of 20 \\
\hline Grammatical accuracy & 4 out of 20 \\
\hline Interactional strategies & 4 out of 20 \\
\hline Total score & 20 out of 20 \\
\hline
\end{tabular}

Table 1. Numerical rating of the speaking proficiency rubric

Each participant in every pair was evaluated on individual basis where row scores (i.e., the total number of correct items (row score $=$ the total score possible - the cumulative penalties due to errors) (Henning, 1987) for each criterion were added and then divided by the number of errors and language items that second year students might encounter in their spoken language. The final row score for each criterion is transformed to percentage according to a linear transformation format (Henning, 1987, p.28): $\mathrm{Y}=\mathrm{X} 100 / C$

$\mathrm{Y}$ : the percentage score

$\mathrm{X}$ : the raw score

C: the total number of items (i.e., the highest possible score) 
Finally, the percentage score was matched with the 4 marks of each criterion as follows: $(0 \%-25 \%)=1 /(26 \%-50 \%)=2 /(51 \%-75 \%)=3 /(76 \%-100 \%)=4$.

Afterwards, the obtained marks for each criterion were added to form the final pre/post speaking test score of each participant.

The table below shows the mean scores and the standard deviation of both speaking pre/post-tests of experimental groups:

\begin{tabular}{|l|l|l|l|}
\hline $\begin{array}{l}\text { Experimental group } \\
\mathbf{1}\end{array}$ & Mean & Std. Deviation & Std. Error \\
\hline Pre-test score & 9.5 & 2.31 & 0.56 \\
\hline Post-test score & 10.77 & 2.49 & 0.60 \\
\hline $\begin{array}{l}\text { Experimental group } \\
\mathbf{2}\end{array}$ & Mean & Std. Deviation & Std. Error \\
\hline Pre-test score & 9.83 & 2.10 & 0.50 \\
\hline Post-test score & 11 & 1.52 & 0.36 \\
\hline
\end{tabular}

Table 2. Descriptive statistics of pre/post speaking skill mean score

The results fairly show difference between the pre-test mean and posttest meanof both experimental groups. These results clearly indicate on one hand that students achieved improvement in their speaking proficiency as their final means (11) and (10.77) are higher than the initial means (9.83) and (9.5) and the standard deviation of the pre-test scores are (2.10) and (2.31), on the other hand,the results indicate that these groups have major differences in their speaking skills. Thus, these groupsare mixed ability groups. While, the standard deviation for the post-test scores for the experimental group 2 (1.52) is lower than the pre-test standard deviation (2.10), the standard deviation of the post-test for the experimental group 1 (2.49) has been increased in comparison to the initial standard deviation (2.31). Consequently, although the experimental group 2 decreased the internal speaking individual differences, the experimental group 1 expanded the gap between the students' speaking level.

To see whether these differences between the pre-and the posttests are statistically significant, the paired scores for each participant in both experimental groups were analysed for any statistical difference using dependent t-test as shown in Table 3, below:

\begin{tabular}{|l|l|l|l|l|l|l|}
\hline Groups & N & Mean & $\begin{array}{l}\text { Std. } \\
\text { deviation }\end{array}$ & t & df & Sig. \\
\hline $\begin{array}{l}\text { Experimental } \\
\text { group 1 }\end{array}$ & 18 & -1.33 & 2.37 & -2.33 & 17 & $\begin{array}{l}2.11 \\
\mathrm{P}<0.025\end{array}$ \\
\hline $\begin{array}{l}\text { Experimental } \\
\text { group 2 }\end{array}$ & 18 & -1.27 & 2.00 & -2.64 & 17 & $\begin{array}{l}2.11 \\
\mathrm{P}<0.025\end{array}$ \\
\hline
\end{tabular}

Table 3. The dependent t-test for speaking

As the above table shows, the $t$ value for both the experimental groups $(2.33, \mathrm{p}<.025)$ and $(2.64, \mathrm{P}<.025)$. Both obtained $t$ values observed are higher 
The Effect of Using Simulation Activities on Developing Algerian EFL Students' Speaking and Listening Proficiency

than the critical value of $\mathrm{t}(2.11)$ in the t- table with the degree of freedom of 17 $(\mathrm{df}=17)$ and the level of significance of 0.025 for the one-tailed hypothesis.

Listening skills tests: pre/post-intervention

The researcher assessed students' listening proficiency on the 20 points scale. Both experimental groups took the listening tests on the same day.

\begin{tabular}{|l|l|l|ll|}
\hline $\begin{array}{l}\text { Experimental group } \\
\mathbf{1}\end{array}$ & Mean & Std. Deviation & $\begin{array}{l}\text { Std. Error } \\
\text { Mean }\end{array}$ & (2.4) \\
\hline Pre-test score & 7.48 & 3.40 & 0.82 & \\
\hline Post-test score & 11.55 & 3.54 & 0.85 & \\
\hline $\begin{array}{l}\text { Experimental group } \\
\mathbf{2}\end{array}$ & Mean & Std. Deviation & $\begin{array}{l}\text { Std. Error } \\
\text { Mean }\end{array}$ & \\
\hline Pre-test score & 8.36 & 2.42 & 0.58 & \\
\hline Post-test score & 11.25 & 3.84 & 0.93 & \\
\hline
\end{tabular}

Table 4. Descriptive statistics of pre/post listening skill mean score

Table 4 indicates the fairly big difference between the pre-test mean and post-test mean of both experimental groups. These results clearly reveal that students achieved improvement in their listening proficiency as their final means (11.55) and (11.25) are higher than the initial means (7.48) and (8.36). The standard deviations of the pre-test scores (3.40) and (2.42) show that these groups have major difference in their listening skills as well. Thus, these groups are mixed ability groups at the beginning of the study. While, the standard deviation for the post-test scores for both experimental groups (3.54) and (3.84) are higher than the pre-test standard deviation (3.40) and (2.42) respectively; this means that the internal variance of the listening skills has increased in both experimental groups and they are still a mixed ability group.

To determine whether these differences between the pre and the posttests are statistically significant, the paired scores for each participant in both experimental groups were analysed for any statistical difference using dependent t-test as shown in Table 5:

\begin{tabular}{|l|l|l|l|l|l|l|}
\hline Groups & N & $\begin{array}{l}\text { Mean } \\
\text { difference }\end{array}$ & $\begin{array}{l}\text { Std. } \\
\text { deviation }\end{array}$ & t & df & Sig. \\
\hline $\begin{array}{l}\text { Experimental } \\
\text { group 1 }\end{array}$ & 18 & -3.48 & 3.22 & -4.46 & 17 & $\begin{array}{l}2.89 \\
\mathrm{P}<0.005\end{array}$ \\
\hline $\begin{array}{l}\text { Experimental } \\
\text { group 2 }\end{array}$ & 18 & -2.91 & 3.39 & -3.54 & 17 & $\begin{array}{l}2.89 \\
\mathrm{P}<0.005\end{array}$ \\
\hline
\end{tabular}

Table 5.Dependent t-test for listening skill

From table 5, the $\mathrm{t}$ values for both the experimental groups are $(4.46, \mathrm{P}<$ $.005)$ and $\quad(3.54, \mathrm{P}<.005)$. They are both higher than the critical value of $\mathrm{t}$ (2.89) in the t- table with the degree of freedom of $17(\mathrm{df}=17)$ and the level of significance of 0.005 for the one-tailed hypothesis. 


\section{Interpretation}

The results revealed that the two experimental groups confirmed the hypotheses stated at the beginning of this research. The speaking and listening proficiency tests results showed the diversity of speaking and listening levels among individual students before the intervention. However, both groups bridged the differences differently. Considering the standard deviation results, on one hand the participants' speaking level discrepancy, in experimental group 1, has increased after the intervention, while the experimental group 2 decreased the internal individual speaking level differences. On the other hand, the listening ability gaps could not be decreased in both experimental groups.

The t-test results revealed better improvements in speaking proficiency in group 2 than group 1. This can be due to the huge gap of speaking proficiency level among students in group 1 that increased at the end of the study. In the other side of the scale, although listening proficiency level in both groups has increased, both groups achieved noticeable development in listening at the end of the study. The inconsistency of the proceeding results can be justified by the influence of the degree of proficiency level divergence on the amount of improvement of the whole group. However, this justification is clearly true for speaking proficiency development and not for listening as the more the speaking proficiency discrepancy is, the less achievement in speaking can reveal. This fact is due to the interactive nature of simulation activities which imposed collaborative learning in the classroom and which apparently failed to match students' level in speaking skills during the simulations. Students learning styles, lack of commitment, personal conflicts, shyness and studentsworking primarily for the final mark lead to speaking and listening proficiency level internal individual distinction. As matter of fact, listening in the test happened in non-interactive way; as a result, students individual capacities were highly developed as the differences did not interfere in the their performance.

\section{Conclusion}

Based on experimental findings, the theoretical review of the positive impact of simulation on developing listening and speaking proficiency meets the findings of this study that proved the efficacy of simulation activities in EFL. The results of the dependent t-test confirmed the estimation stated in this study that simulation activities improved the EFL students listening and speaking proficiency. This conclusion encourages using innovative teaching techniques, using drama and games to help EFL learners to adopt their language to the changes of the language use requirements.

Furthermore, this study highlighted the positive effect of using taskbased teaching in the language classroom to develop oral proficiency. Using 
tasks, like simulation, not only generates communication, but leads to activating learners and providing fun and rigorous teaching environment as well. English language teachers should understand the mechanics of simulation activities for better applications in the classroom to teach not only oral skills but also to raise students' cultural awareness in their English classes. For successful simulations, EFL teachers should encourage learners to take further responsibilities jointly with their partners to reduce the proficiency gap among them while interacting in the simulation.

\section{REFERENCES}

Bachman, L. (1990). Fundamental considerations in language testing.Oxford: Oxford University Press.

Barker, L. L., \& Gaut, D. R. (2002).Communication (8th ed.). Boston, MA: Allyn and Bacon.

Brown, H. D. (2001).Teaching by principles: An interactive approach to language pedagogy ( $2^{\text {nd }} \mathrm{ed}$.). New York: Longman.

Buck, Gary. (2001).Assessing listening.Cambridge: Cambridge University Press.

Bygate, Martin. (1987).Speaking. Oxford: Oxford University Press.

Canal, M. (1983).From communicative competence to communicative language pedagogy. In Richards, J. and Schmidt, R. (eds.), Language and Communication. Harlow: Longman.

Celce-Murcia, M.; Dornyei, Z. and Thurrel, S. (1995).Communicative competence: A pedagogically motivated model with content specifications. Issues in Applied Linguistics, 6 (2). Retrieved from http://www.zoltandornyei.co.uk/uploads/1995-celce-murcia-dornyeithurrell-ial.pdf

Field, John. (2008). Listening in the language Classroom. Cambridge: Cambridge University.

Fulcher, G. (2003).Testing second language speaking. London: Pearson Longman.

Galaczi, E. (2005). Upper main suite speaking assessment: Towards an understanding of assessment criteria and oral examiner behaviour, Cambridge ESOL Research Notes 20, 16-

19.http://www.cambridgeesol.org/rs_notes/rs_nts20.pdf

Harmer, Jeremy. (2007). The practice of English language teaching. $4^{\text {th }} \mathrm{ed}$. Harlow, England: Pearson: Longman.

Henning, G. (1987). A guide to language testing: development, evaluation, research. Cambridge, Mass.: Newberry House Publishers. 
Jones, K. (1982).Simulations in language teaching. Cambridge University Press, Cambridge.

Jones, L. (1983).Eight simulations. Cambridge: Cambridge University Press.

Ladousse, G. P. (1987). Role play. Oxford: Oxford University Press.

Littlewood, W. (1981).Communicative language teaching. Cambridge: Cambridge University Press.

O'Malley, J. Michael, \& Valdez Pierce, Lorraine. (1996).Authentic assessment for English language learners: Practical approaches for teachers. London: Longman.

Richards, Jack C. (2008).Teaching listening and speaking: From theory to practice. Cambridge: Cambridge University Press.

Shaw, Carolyn M. (2010).Designing and using simulations and role-play exercises.The International Studies Encyclopedia. (Ed) Robert A. Denemark. 15. Nov. 2015. DOI 10.1111/b.9781444336597.2010.x

Thornbury, S. (2005). How to teach speaking. Harlow, England: Longman.

Vandergrift, Laurens. (1997).The Cinderella of Communication Strategies: Reception Strategies in Interactive Listening. The Modern Language Journal, 81(4), 494-496.Retrieved from http://www.jstor.org/stable/328892

Weir, Cyril J. (2005).Language testing and validation: An evidence-based approach. Palgrave Macmillan: Great Britain.

Xiaoxian, Guan \& Yan, Jin. (2010). Interactive listening: Construct definition and operationalization in tests of English as a foreign language.Chinese Journal of Applied Linguistics, 33(6), 22.

Appendix: Analytic speaking Rubric (Weir, 1993)

Fluency

4. Generally natural delivery, only occasional halting when searching for appropriate words/expressions.

3. The student hesitates and repeats himself at times but can generally maintain a flow of speech, although s/he may need an occasional prompt.

2. Speech is slow and hesitant. Maintains speech in a passive manner and needs regular prompts.

1. The student speaks so little that no 'fluent' speech can be said to occur.

The main phenomena considered in the four ratings of fluency are (Fulcher,2003):

- Hesitations (pauses unfilled or filled with noises like 'erm')

- Repeating syllabus or words.

- Changing words.

- Correcting the use devices, particularly pronouns.

- Changing the structure of the utterance.

- Cohesion 
The Effect of Using Simulation Activities on Developing Algerian EFL

Students' Speaking and Listening Proficiency

\section{Pronunciation}

4. Occasional errors of pronunciation a few inconsistencies of rhythm, intonation and pronunciation but comprehension is not impeded.

3. Rhythm, intonation and pronunciation require more careful listening; some errors of pronunciation which may occasionally lead to incomprehension.

2. Comprehension suffers due to frequent errors in rhythm, intonation and pronunciation.

1. Words are unintelligible.

The phonetic structure considered the following pronunciation errors (Fulcher,2003):

- Single word pronunciation.

- Stress

- Intonation

Vocabulary

4. Effective use of vocabulary for the task with little inappropriacy.

3. For the most part, effective use of vocabulary for the task with some examples of inappropriacy.

2. Limited use of vocabulary with frequent inappropriacy.

1. Inappropriate and inadequate vocabulary.

\section{Grammatical accuracy}

4. Very few grammatical errors evident.

3. Some errors in use of sentence structures and grammatical forms but these do not interfere with comprehension.

2. Speech is broken and distorted by frequent errors.

1. Unable to construct comprehensible sentences.

The high gravity grammatical errors considered in the ratings above $\operatorname{are}($ Fulcher,2003):

- Subject verb agreement

- Tense selection

- Pronouns or relative pronouns use.

- Mis-selection of preposition 


\section{Interactional strategies}

4.Interacts effectively and readily participates and follows the discussion.

3. Use of interactive strategies is generally adequate but at times experiences some difficulty in maintaining interaction consistently.

2. Interaction ineffective can seldom develop an interaction.

1.Understanding and interaction minimal.

In this criterion, the term 'interactional strategies' means using strategies such as

- Initiatingthe discussion, turn taking, repair, and closing(Fulcher,2003).

Besides paying attention to the following language functions:

- Asking for clarification, expanding the topic, expressing opinion, paraphrasing, andagreeing/disagreeing. 